\title{
Enteric coated HPMC capsules plugged with 5-FU loaded microsponges: a potential approach for treatment of colon cancer
}

\author{
Ankita Gupta, ${ }^{1, *}$, Gaurav Tiwari $^{1}$, Ruchi Tiwari ${ }^{1}$, Rishabh Srivastava ${ }^{2}$, A. K. Rai ${ }^{1}$ \\ ${ }^{1}$ Pranveer Singh Institute of Technology, Bhauti, Kanpur (UP), India, ${ }^{2}$ Akums Drugs and Pharmaceuticals Limited, \\ Haridwar, India
}

\begin{abstract}
The work was aimed at developing novel enteric coated HPMC capsules (ECHC) plugged with 5 Florouracil (5-FU) loaded Microsponges in combination with calcium pectinate beads. Modified quasiemulsion solvent diffusion method was used to formulate microsponges based on $3^{2}$ factorial design and the effects of independent variables (volume of organic solvent and Eudragit RS100 content) on the dependent variables (Particle size, \%EE \& \% CDR) were determined. The optimized microsponges (F4) were characterized by SEM, PXRD, TGA and were plugged along with calcium pectinate beads in HPMC capsules and the HPMC capsules were further coated with enteric polymer Eudragit L 100 (Ed-L100) and/ or Eudrgit S 100 (Ed-S 100) in different proportions. In vitro release study of ECHC was performed in various release media sequentially SGF for $2 \mathrm{~h}$, followed by SIF for the next $6 \mathrm{~h}$ and then in SCF (in the presence and absence of pectinase enzyme for further $16 \mathrm{~h}$ ). Drug release was retarded on coating with EdS-100 in comparison to blend of EdS-100: EdL-100 coating. The percentage of 5-FU released at the end of $24 \mathrm{~h}$ from ECHC 3 was $97.83 \pm 0.12 \%$ in the presence of pectinase whereas in control study it was $40.08 \pm 0.02 \%$ drug. The optimized formulation was subjected to in vivo Roentgenographic studies in New Zealand white rabbits to analyze the in vivo behavior of the developed colon targeted capsules. Pharmacokinetic studies in New Zealand white rabbits were conducted to determine the extent of systemic exposure provided by the developed formulation in comparison to 5-FU aqueous solutions. Thus, enteric coated HPMC capsules plugged with 5-FU loaded microsponges and calcium pectinate beads proved to be promising dosage form for colon targeted drug delivery to treat colorectal cancer.
\end{abstract}

Uniterms: 5-Fluorouracil. HPMC capsules/enteric coating. Microsponges/formulation. Drugs/delivery/ colon targeting. Colorectal cancer/treatment.

O trabalho teve como objetivo o desenvolvimento de novas cápsulas com revestimento entérico HPMC (ECHC) conectadas com microesponjas carregadas com fluoruracila (5-FU) em combinação com grânuos de pectinato de cálcio. O método de difusão de solvente modificado quasi-emulsão foi usado para formular microesponjas com base no planejamento fatorial $3^{2} \mathrm{e}$ determinaram-se os efeitos das variáveis independentes (volume de solvente orgânico e conteúdo Eudragit RS100) sobre as variáveis dependentes (tamanho de partícula, EE\% e \% CDR). As microesponjas otimizadas (F4) foram caracterizadas por SEM, PXRD, TGA e ligadas aos grânulos de pectinato de cálcio em cápsulas de HPMC e estas foram, ainda, revestidas com polímero entérico Eudragit L 100 (Ed-L100) e/ou Eudrgit S 100 (Ed S 100) em diferentes proporções. No estudo de liberação in vitro de ECHC foi realizada em vários meios de liberação sequencial SGF durante $2 \mathrm{~h}$, seguido de SIF para as próximas $6 \mathrm{~h}$, e, em seguida, em SCF (na presença e na ausência de enzima pectinase por mais $16 \mathrm{~h}$ ). A liberação do fármaco foi retardada em revestimento com a EDS-100, em comparação com mistura de EDS-100: EDL-100, de revestimento. O percentual de 5-FU liberado de ECHC 3 ao final de $24 \mathrm{~h}$ foi $97,83 \pm 0,12 \%$ em presença de pectinase, enquanto que para o controle foi de $40,08 \pm 0,02 \%$ do fármaco. A formulação otimizada foi submetida a estudos Roentgenográficos in vivo, em coelhos brancos Nova Zelândia, para analisar o comportamento das cápsulas desenvolvidas direcionadas ao cólon. Os estudos de farmacocinética em coelhos brancos da Nova Zelândia foram conduzidos para determinar a extensão da exposição sistêmica propiciada pela formulação desenvolvida, em comparação com solução aquosa de 5-FU. Assim, cápsulas entéricas de HPMC revestidas e conectadas com microesponjas

\footnotetext{
*Correspondence: Ankita Gupta. Pranveer Singh Institute of Technology. Kalpi Road, Bhauti, 208020 - Kanpur - UP, India. E-mail: gupta.ankita483@gmail.com
} 
carregadas com 5-FU e grânulos de pectinato de cálcio se mostraram promissoras como formulação para liberação do fármaco no cólon no tratamento do câncer colorretal.

Unitermos: Fluoruracila. Cápsula de HPMC/revestimento entérico. Microesponjas/formulação. Fármaco/ liberação/direcionamento para o cólon. Câncer colorretal/tratamento.

\section{INTRODUCTION}

Cancer is one of the most challenging diseases to cure and the second leading cause of death in developing countries. Over the past few decades, it continues to be a worldwide health problem in spite of several advanced technologies (Wolpin, Mayer, 2008). Cancers of the colon and rectum, often collectively referred to as colorectal cancer, are life-threatening tumors that develop in the large intestine. More than $80 \%$ of colorectal tumors develop from adenomatous polyps. Their numbers increase with age. Polyps are found in about $25 \%$ of people by age 50 , and $50 \%$ of people by age 75 . Fewer than $1 \%$ of polyps less than 1 centimeter (slightly less than half an inch) becomes cancerous. About $10 \%$ of larger polyps become cancerous within 10 years, and about $25 \%$ of these larger polyps become cancerous after 20 years.

Drug delivery systems based on calcium pectinate beads have been recently investigated for specifictargeting drugs to the colon (Badve et al., 2007). Such systems, obtained by pectin gelatinization in the presence of calcium salts, are less water-soluble than natural pectins, since calcium ions induce non-covalent associations of carbohydrate chains through the formation of the so-called "egg box complexes" but they maintain the selective biodegradation by pectinolytic enzymes of colonic bacteria microflora (Jain, Gupta, Jain, 2007).

Microsponges are polymeric delivery systems composed of porous microspheres. They are tiny sponge like spherical particles that consist of a myriad of interconnecting voids within a non-collapsible structure with large porous surface (Srivastava, Kumar, Pathak, 2010). The reasons for fabricating microsponge was due to the fact that, drug carrier systems less than $200 \mu \mathrm{m}$ can efficiently be taken up by the macrophages present in colon tissue, thus exhibit effective localized drug action at the desired site. Apart from being site specific, retention of drug or its carrier system on the colonic surface is yet another important consideration that guided the selection of microsponges as the drug carrier system in the research work (Orlu, Cevher, Araman, 2006). They can also increase the lag time for absorption of drug as these get entrapped on the surface of the colon and thus have the potential for being developed as a colon-targeted drug delivery system.
The objective of our research work was to design novel enteric coated HPMC capsules (ECHC) plugged with 5-FU loaded microsponges in combination with calcium pectinate beads. $3^{2}$ full factorial design was used to optimize microsponges prepared by modified quasi-emulsion solvent diffusion method using a sodium chloride as porogen.

5-FU was chosen as a model drug for our research work because targeted delivery of 5-FU not only reduces systemic side-effects, but also provide an effective and safe therapy for colon cancer with reduced dose and reduced duration of therapy (Chickpetty, Raga, 2013). Longer exposure to lower concentration of 5-FU has been reported by researchers to favor DNA-directed effects which is thought to contribute to its anti-tumor effect .

In our research work HPMC capsule was preferred over gelatine capsules because HPMC capsule had slower drug release profile in acidic media and the fast release profile at a $\mathrm{pH}$ of 5 and above (Huyghebaert, Vermeire, Remon, 2004). This can result in lower quantities of polymer coat compared with that required for tablets to achieve the desired release in the small intestine or colon. Surprisingly, it was also found that enteric coated HPMC capsules offer much higher resistance against acid solutions as compared to enteric coated gelatine capsules (Moawia, Tabakha, 2010).

\section{MATERIAL AND METHODS}

\section{Material}

5-FU (Shalaks Pharmaceutical Pvt. Ltd, New Delhi); HPMC Capsules (ACG Associated Capsules Pvt. Ltd, SciTech Centre, Mumbai); Eudragit RS100, Eudragit S100 (EdS100) and Eudragit L100 (EdL100) (Evonik Labs, Mumbai) were obtained as gifts from the suppliers. All other chemicals used were of analytical grade and purchased from authentic suppliers.

\section{Method development for the fabrication of microsponges}

Previously described methods of microsponge preparation by quasi emulsion solvent diffusion technique 
using porogen (Bae et al., 2009; Graves et al., 2005) were modified to employ an aqueous solution of sodium chloride as porogen. $1 \%(\mathrm{w} / \mathrm{v})$ aqueous solution of the porogen $(\mathrm{NaCl})$ was prepared and sufficient amount of Span 80 was added to it with agitation to obtain $1 \%(\mathrm{v} / \mathrm{v})$ dispersion. A solution of the Eudragit RS 100 and 5-FU was prepared in a mixture of Ethanol: DCM and the porogen solution $(0.1 \mathrm{~mL})$ was uniformly emulsified in it, to form a w/o emulsion. $5 \%(\mathrm{w} / \mathrm{v})$ aqueous PVA solution (external phase) was prepared separately and the previously prepared w/o emulsion was emulsified in it. This $\mathrm{w} / \mathrm{o} / \mathrm{w}$ emulsion was stirred for $24 \mathrm{~h}$ to get microsponges that were filtered, dried at $60{ }^{\circ} \mathrm{C}$ and stored in a desiccator (Srivastava, Kumar, Pathak, 2010).

\section{Optimization of microsponges via $3^{2}$ factorial design}

A $3^{2}$ randomized full factorial design was run to optimize the variables. In this design two factors were evaluated, each at 3 levels, and experimental trials were performed at all nine possible combinations using Design Expert Software 8.0.7.1 (Stat-Ease, Inc., Minneapolis, USA). In the present investigation, volume of organic media $\left(\mathrm{X}_{1}\right)$ and amount of polymer content $\left(\mathrm{X}_{2}\right)$ were selected as independent variables and total nine microsponge formulations (F1-F9) were fabricated by varying these variables as given in Table I. The particle size, \% EE and \% CDR selected as dependent variables and Polynomial equations were generated for the dependent variables that were reduced by removing non-significant coefficients by applying one way ANOVA. To demonstrate graphically the influence of each factor on the responses, the response surface plots and $3 \mathrm{D}$ bar graph were generated. The value of $\mathrm{P}<0.05$ was considered to be significant.

- Validation of experimental design

The formulation developed was evaluated for the responses and the experimental values obtained were compared with those predicted by the mathematical models generated (F 10).

- Selection of optimized formulation

A numerical optimization technique using the desirability approach was employed to select the optimized formulation with desired responses. Constraints like maximizing entrapment efficiency \& \% drug release at the end of $8 \mathrm{~h}$ as well as minimizing particle size were set as goals to select the optimized formulation using Design Expert Software 8.0.7.1 (Stat-Ease, Inc., Minneapolis, USA). Optimized formulation was plugged in enteric coated colon target capsules.

\section{Characterization of microsponges}

- Morphological studies and rheological characterization

Morphological characteristics of microsponges were studied by scanning electron microscopy (Hitachi, S $3000 \mathrm{H}$ Japan). The microsponges were dotted on an adhesive tape attached to an aluminium stub and excess microsponges were detached. To render the particles electrically conductive, the stub spotter was coated with gold using a vacuum evaporator. The coated Microsponges were viewed at $10 \mathrm{kV}$.

TABLE I - $3^{2}$ Factorial design model for the fabrication of 5-FU loaded microsponges

\begin{tabular}{|c|c|c|c|c|}
\hline \multirow[b]{2}{*}{ S. No. } & \multirow[b]{2}{*}{ Formulation Code } & \multicolumn{2}{|c|}{ Independent Variables } & \multirow[b]{2}{*}{ Dependent Variables } \\
\hline & & $\begin{array}{l}\text { Volume of Organic Media } \\
(\mathrm{mL})\left[\mathrm{X}_{1}\right]\end{array}$ & $\begin{array}{l}\text { Polymer Content } \\
\quad(\mathrm{mg})\left[\mathrm{X}_{2}\right]\end{array}$ & \\
\hline$\overline{1}$ & F1 & $(+1) 8$ & $(+1) 1200$ & Particle Size $\left(\mathrm{Y}_{1}\right)$ \\
\hline 2 & F2 & $(-1) 6$ & $(-1) 400$ & $\% \mathrm{EE}\left(\mathrm{Y}_{2}\right)$ \\
\hline 3 & F3 & (0) 7 & (0) 800 & $\% \mathrm{CDR}\left(\mathrm{Y}_{3}\right)$ \\
\hline 4 & $\mathrm{~F} 4$ & $(+1) 8$ & $(-1) 400$ & \\
\hline 5 & F5 & $(-1) 6$ & $(+1) 1200$ & \\
\hline 6 & F6 & $(0) 7$ & $(-1) 400$ & \\
\hline 7 & F7 & $(-1) 6$ & (0) 800 & \\
\hline 8 & F8 & $(0) 7$ & $(+1) 1200$ & \\
\hline 9 & F9 & $(+1) 8$ & $(0) 800$ & \\
\hline 10 & F10 (extra design check point) & $(+0.5) 7.5$ & $(-0.5) 600$ & \\
\hline
\end{tabular}


- $\quad$ Powder X-ray diffraction studies (PXRD)

The crystalline behavior of the drug before and after encapsulation, was evaluated by X-ray powder diffractometer (Bruker D8 Discover, Germany) using a $\mathrm{CuK}$ alpha radiation source with the Ni-filter. A scanning rate of $5^{\circ} \mathrm{min}^{-1}$, tube voltage of $35 \mathrm{KV}$ and current of 35 $\mathrm{mA}$ over a range of $16-60^{\circ}$ were used in measurement.

\section{- Thermal analysis}

Differential scanning calorimetry and Thermo gravimetric analysis of the pure drug and drug-loaded microsponges were carried out with simultaneous TGA / DSC analyzer (Mettler Toledo TGA/ DSC, USA). An amount $13.714 \mathrm{mg}$ of drug and $9.35 \mathrm{mg}$ of drug loaded microsponges was placed in aluminium pans and sealed prior to the test. All samples were run at a heating rate of $10{ }^{\circ} \mathrm{C} / \mathrm{min}$ over a temperature range $30-600{ }^{\circ} \mathrm{C}$ in an atmosphere of nitrogen.

\section{- $\quad$ Particle size}

All Formulations of the microsponges were analyzed for particle size by an optical microscope. The instrument was calibrated and found that 1 unit of eyepiece micrometer was equal to $7 \mu \mathrm{m}$. Sizes of 100 microsponges were calculated in $10 \mathrm{X}$ magnification.

- Determination of drug content, drug loading and entrapment efficiency (EE)

A sample of drug loaded microsponges $(50 \mathrm{mg}$ ) was dissolved in $50 \mathrm{~mL}$ of phosphate buffer ( $\mathrm{pH} 7.4$ ) by using ultrasonicator and kept for overnight. Filtered Samples were appropriately diluted and analyzed spectrophotometrically at $266 \mathrm{~nm}$. Percent drug content, $\%$ entrapment efficiency and \% drug loading were calculated.

- In vitro drug release studies of microsponges

Microsponges equivalent to $50 \mathrm{mg}$ of drug were filled in HPMC capsules and placed in the basket (mesh $\# 230=63 \mu \mathrm{m}$ ) of USP apparatus 1 and the study was performed in the $900 \mathrm{~mL}$ of simulated colonic fluid (SCF) without pectinase for $8 \mathrm{~h}$ at $50 \mathrm{rpm}$, maintained at $37 \pm 0.5^{\circ} \mathrm{C}$. Aliquots were withdrawn periodically and sink conditions were maintained by adding equal amounts of release medium. The samples were analyzed spectrophotometrically and \% cumulative drug release (CDR) versus time plots was constructed. Data obtained from in-vitro release studied was evaluated to check the goodness of fit to various release kinetics equations for quantifying the phenomena controlling the release of drug from microsponges (Costa, Lobo, 2001).

\section{Modification of pectin and its characterization}

Pectin was crosslinked by the ionotropic gelation method. A $10 \%(\mathrm{w} / \mathrm{v})$ aqueous Pectin dispersion was added drop wise into gently stirred $100 \mathrm{~mL}$ of $10 \%(\mathrm{w} / \mathrm{v})$ aqueous solution of calcium chloride pre-adjusted to $\mathrm{pH}$ 5.5. The gelled particles were left in the medium for 10 min, washed with deionized water and dried at $60^{\circ} \mathrm{C}$. The particles were screened through sieve no 44 and kept in a desiccator to remove the traces of moisture and then evaluated for morphological, rheological and swelling characteristics (Sharma, Philip, Pathak, 2008).

\section{Preparation and evaluation of enteric coated HPMC capsules}

Each batch of HPMC capsules was coated with enteric polymer EdS100 / EdL100 or bend of EdS100 and EdL100 in different ratios, by dip coating method in the polymeric solution of EdS100 and EdL100 to ensure the formation of a uniform and thin covering over the capsule. In order to enhance the elasticity of EUDRAGIT films, $1.25 \%$ of dibutyl phthalate as plasticizer was added to the coating solution. HPMC bodies and caps were coated separately to ensure coverage of the body with polymer, especially where the cap overlaps (Huyghebaert, Vermeire, Remon, 2004). Coated bodies were filled by formulation matrix consisting of $50 \mathrm{mg}$ drug loaded microsponges plugged along with $5,10,15 \% \mathrm{w} / \mathrm{w}$ of calcium pectinate beads and the rest of the volume was adjusted by inert lactose and finally closed with the coated caps. The joint of the capsule was sealed with a small amount of 5\% EdS 100 solution. For each polymeric solution coating of the capsules was made with different thickness ratios. The capsules were allowed to dry with the help of dryer with an inlet temperature of $35-40{ }^{\circ} \mathrm{C}$ and observed for coat uniformity, pores and cracks under microscope.

\section{- Integrity test of enteric coated HPMC capsules}

Prior to the dissolution test enteric-coated HPMC capsules were subjected to a disintegration test in $0.1 \mathrm{M}$ $\mathrm{HCl}$ for $2 \mathrm{~h}$ to determine the ability of the coat to withstand acid environment. Afterwards, the capsules were dried at $25^{\circ} \mathrm{C}$ for $45 \mathrm{~min}$, thereafter; the capsules were subjected to microscopic examination to check for the integrity of the coat. The enteric coated capsules, which passed the disintegration test were further evaluated for integrity of the coating in $\mathrm{pH} 5.5$ since the dissolution of the coating in $\mathrm{pH}$ lower than 6.8 may alter the required lag time. On the basis of solubility in $\mathrm{pH} 5.5$ buffer, coating compositions and levels that fell short were rejected to avoid alteration 
of lag time. Only coating levels and compositions which were not dissolved at all or dissolved very slowly in $\mathrm{pH}$ 5.5 buffer were selected for further in vitro drug release studies (Cole et al., 2002).

\section{- In vitro drug release study of ECHC}

The study was performed in USP drug release apparatus in various release media sequentially SGF $(\mathrm{pH}$ 1.2) for $2 \mathrm{~h}$, followed by SIF ( $\mathrm{pH} 7.4$ ) for the next $6 \mathrm{~h}$ and then in SCF (presence and absence of pectinase, for further $16 \mathrm{~h}$ ). The test conditions were $900 \mathrm{ml}$ of medium stirred at $50 \mathrm{rpm}$ and maintained at $37 \pm 0.5^{\circ} \mathrm{C}$. Aliquots were withdrawn at regular intervals and replaced with an equal amount of the fresh medium to maintain sink condition. The samples were analyzed for 5-FU content released at $265.4 \mathrm{~nm}$. Concomitantly the swelling characteristics and physical behavior of capsules were observed at $0,2,5,8$, $10,14,18$ and $24 \mathrm{~h}$ and recorded visually. The systematic evaluation of ECHC-3, ECHC-14, and ECHC-15 led to identification of optimized formulation.

\section{Animal studies}

All the animal experiments have been conducted in full compliance with the institutional ethical and regulatory principles and as per the spirit of the Association for Assessment and Accreditation of Laboratory Animal Care \& International's expectations for animal care and use/ethics committees. The investigations were performed after obtaining approval by the Institutional Animal Ethical Committee of PSIT, Kanpur, India (IAEC no: IAEC/PSIT/1273/ac/13).

\section{- In vivo roentgenographic study}

The 5-FU loaded microsponges in colon targeted capsules were partially replaced with barium sulfate microsponges (Chickpetty, Raga, 2013). The reformulated enteric polymer coated capsules were administered orally with $15 \mathrm{ml}$ of water, to New Zealand white rabbits $(\mathrm{n}=3$; $3-3.5 \mathrm{~kg}$ ) that were fasted overnight with free access to water. Fluoroscopic images of the abdomen of the rabbits were taken before administration $(0 \mathrm{~h})$ and at $1.5 \mathrm{~h}, 3.5 \mathrm{~h}, 5$ $\mathrm{h}, 7.5 \mathrm{~h}$ and $10 \mathrm{~h}$ to trace the in vivo movement and behavior of capsules in the gastrointestinal tract. X-ray images of the rabbits in prone position were captured using L\&T Vision 100 (C-arm) X-ray machine (Larsen and Tourbo Limited, Mumbai, India), at $64 \mathrm{mAs}$ and $63 \mathrm{kV}$ voltage.

\section{- In vivo pharmacokinetics study}

New Zealand white rabbits weighing 3-3.5 kg were classified in two groups, namely standard and test with three animals in each group. The animals were fasted overnight with free access to water. The standard group received 5-FU aqueous solutions ( $10 \mathrm{mg} / \mathrm{kg})$, while the test group received colon targeted capsules (ECHC-3). At appropriate intervals, blood samples (approximately 1 $\mathrm{ml}$ ) were withdrawn from the marginal ear vein. 5-FU was extracted from plasma by mixing rabbit plasma with ethyl acetate and isopropyl alcohol $(85 / 15, \mathrm{v} / \mathrm{v})$. The samples were then dried with $\mathrm{N}_{2}$ at $37^{\circ} \mathrm{C}$ and the dehydrated samples were dissolved in $400 \mu$ of mobile phase for subsequent HPLC. The concentration of releasing 5-FU was measured using reversed-phase HPLC (HP1100 Liquid Chromatography, Agilent). A Hypersil C18 (5 $\mu \mathrm{m}$, ID $4.6 \mathrm{~mm} \times 300 \mathrm{~mm}$ ) analytical column was used with a mobile phase of $0.01 \mathrm{~mol} / \mathrm{L}$ phosphate buffer $(\mathrm{pH} 3.0)$ and an elution rate of $1.0 \mathrm{~mL} / \mathrm{min}$ at room temperature. Absorbance at $269 \mathrm{~nm}$ was monitored and pharmacokinetic parameters were determined from the absorbance-time curves. This method provided complete separation with a corresponding retention time of 7.0 minutes for 5 -FU. The area under the plasma drug concentration-time curve was calculated using the trapezoidal rule. The maximal plasma concentration of drug $(C \max )$ and the time to reach the maximum plasma concentration ( $T$ max) were directly obtained from plasma data (Ramasamy et al., 2011). The data from different formulations were compared for statistical significance by one-way analysis of variance (ANOVA). All results were expressed as mean \pm S.D.

\section{RESULT AND DISCUSSION}

\section{Method development for the fabrication of microsponges}

In present research work, sodium chloride was used as porogen, based on the considerations that the use of hydrogen peroxide and sodium bicarbonate as porogen resulted in the evolution of gases like nascent oxygen or carbon dioxide that may be incompatible with active pharmaceutical ingredients. Sodium chloride as a porogen is inert in terms of the evolution of gas and its high aqueous solubility would facilitate its easy extraction in the outer aqueous phase during the microsponge formation (Orlu, Cevher, Araman, 2006). Therefore, using sodium chloride as porogen, nine formulations (F1-F9) were fabricated and characterized.

\section{Characterizations of microsponges}

- Morphological studies and rheological characterization Micrographs of optimized drug loaded microsponges 
F4 confirmed the highly porous nature of microsponges. SEM of microsponges before in vitro release test in Figure 1 (A and B) depicted spherical, smooth surfaced and uniformly porous particles. Figure $1(\mathrm{C}$ and $\mathrm{D})$ magnified the surface view of microsponges F4 will show its highly cross linked polymeric surface containing numerous interconnected voids loaded with drug thus supporting the spongy nature of microsponges. Figure 1 (E and F) is the micrographs of microsponges $\mathrm{F} 4$ after the in vitro drug release for $8 \mathrm{~h}$ and it depicted irregular microsponges with numerous regular striations due to erosion of surface associated drug molecules.
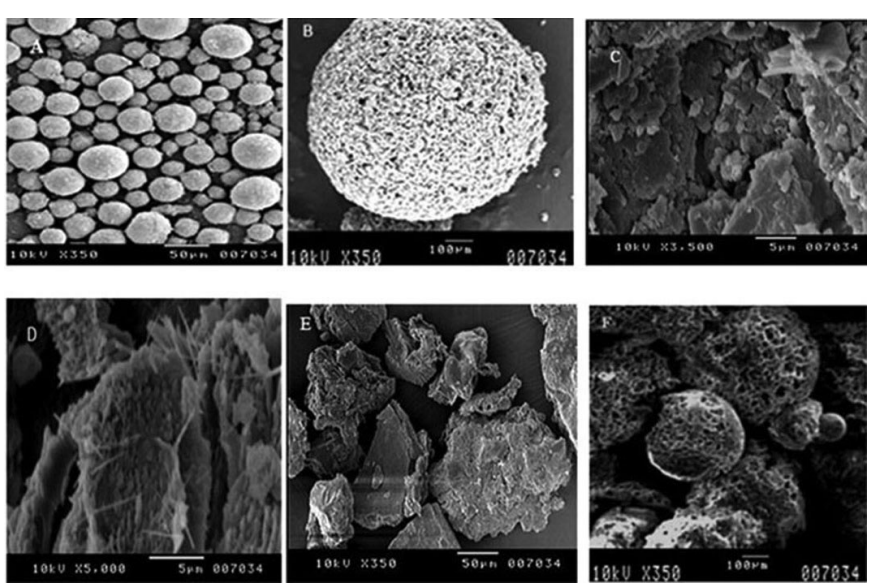

FIGURE 1 - SEM of Microsponges F4 before drug release (A and $\mathrm{B}$ ), surface view of F4 before drug release (C and D), F4 after drug release ( $\mathrm{E}$ and $\mathrm{F})$.

- $\quad$ Powder X- ray diffraction studies (PXRD)

The X-ray diffraction patterns of 5-FU and 5- FU loaded microsponges plotted by using origin software are shown in Figure 2.The PXRD pattern of 5-FU showed peaks at $29^{\circ}, 33^{\circ} 16^{\circ}, 19^{\circ}$, and $21^{\circ}$ which were intense and sharp indicating its crystalline nature also supported by the literature (Zhang et al., 2011). Some of these 5 -FU peaks are also present in diffractogram of 5-FU loaded

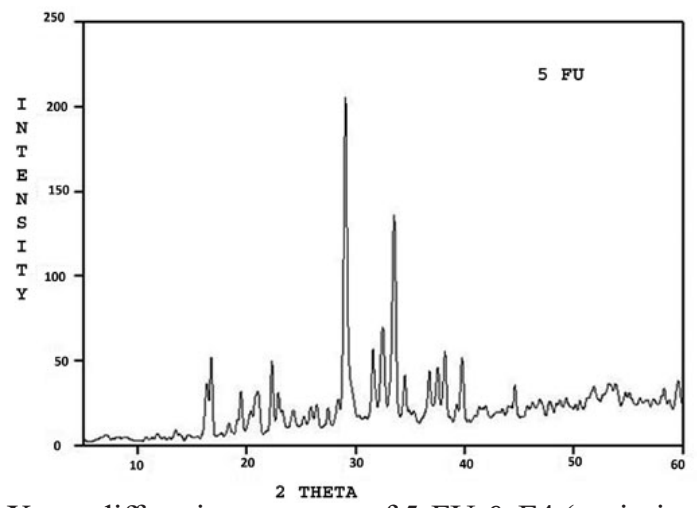

microsponges, due to surface adsorbed drug. Since Eudragit RS 100 has ammonio methacrylate units that confer a positive charge on the polymer surface while 5 -FU has a negative charge on its surface. Therefore the drug molecule can undergo ionic adsorption on the surface of the polymer. However, 5-FU loaded microsponges presented most of the peaks of diminished intensity indicating that there might be partial or complete transitions of drug entrapped in microsponges from crystalline state to an amorphous state.

- Thermal analysis

TGA-DSC thermograms of pure 5-FU and drug loaded microsponges are depicted in Figure 3. The extrapolated onset temperature in thermograms denotes the temperature at which the weight loss begins. The extrapolated onset temperature of $5-\mathrm{FU}$ is $286.9^{\circ} \mathrm{C}$. The DSC thermogram of the pure 5-FU also showed a sharp melting endotherm peak at approximately 286.9 ${ }^{\circ} \mathrm{C}$ followed by decomposition, which was in agreement with those reported previously (Lee et al., 2003). The red curve is the \% weight loss curve and it indicated that $\%$ Weight loss occurs in one step with $90 \%$ decomposition of the drug between $280{ }^{\circ} \mathrm{C}$ to $350{ }^{\circ} \mathrm{C}$. Drug-loaded Optimized microsponges showed TGA extrapolated onset temperature at $280{ }^{\circ} \mathrm{C}$ and $365^{\circ} \mathrm{C}$ indicating the presence of small drug in crystalline form which might be due to small amount of drug adsorbed onto the surface of the microsponges whereas a shifted small broad endothermic peak at $351{ }^{\circ} \mathrm{C}$ suggested that the drug was either totally or partially converted into amorphous form and further no characteristic peak of 5-FU was observed. The reduction of height and sharpness of the endotherm peak may be due to the presence of polymers in the microsponges. TGA thermograms of microsponges also showed a downward shift which indicated loss of mass (due to solvent evaporation, loss of moisture and degradation) upon heating. The red curve, which is the $\%$

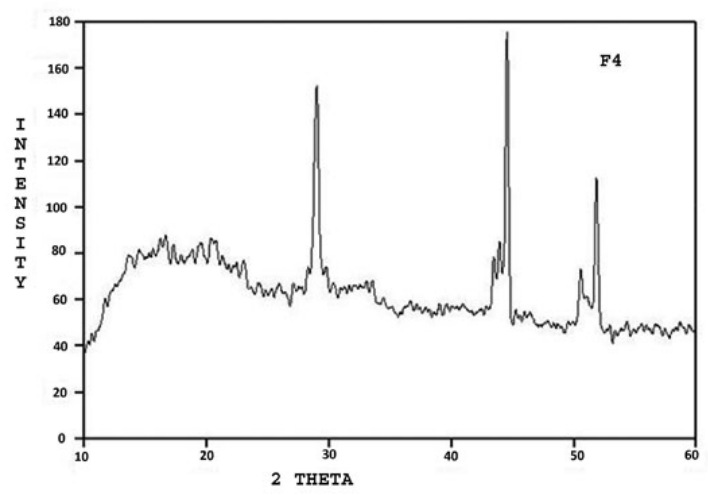

FIGURE 2 - X-ray diffraction patterns of 5-FU \& F4 (optimized 5-FU loaded microsponges). 
weight loss curve showed \% weight loss in two steps. In the first step, $20 \%$ weight loss between $260{ }^{\circ} \mathrm{C}$ to $290{ }^{\circ} \mathrm{C}$ indicated decomposition of surface adsorbed drug present in crystalline form and in the second step, $70 \%$ weight loss in a temperature range of $340{ }^{\circ} \mathrm{C}$ to $410{ }^{\circ} \mathrm{C}$ suggested the decomposition of amorphous form of drug entrapped within the microsponges. Therefore, physical status of drug present in microsponges was in correlation with PXRD data.

\section{Particle size}

The particle size of the microsponges ranged between $41.48 \mu \mathrm{m}$ (F2) and $75.02 \mu \mathrm{m}$ (F9) (Table II). On applying one-way ANOVA, it was observed that the experimental design had significant influence on the particle size. As the amount of the drug to be incorporated was kept constant, any change in particle size was influenced by the variation in the levels of ERS100 (polymer) and the volume of organic solvent. At the lowest level of organic solvent, the microsponges F2, F5 and F7 with mean diameter 61.22 $\mu \mathrm{m}, 71.48 \mu \mathrm{m}$ and $75.02 \mu \mathrm{m}$ respectively were obtained. However, on increasing the volume of organic solvent, microsponges with smaller diameter were formulated. Thus F4 and F9 yielded smaller microsponges of 42.15 and 58.31 respectively. Also at low levels of polymer content, microsponges F2, F4 and F6 with a mean diameter of $61.22 \mu \mathrm{m}, 42.15 \mu \mathrm{m}$, and $55.32 \mu \mathrm{m}$, were obtained. However, on increasing the polymer content, microsponges with larger diameter were formulated, i.e. F1, F5 and F8 with a mean diameter of $69.40 \mu \mathrm{m}, 71.48$ $\mu \mathrm{m}$ and $65.31 \mu \mathrm{m}$ respectively, were obtained. Therefore, it was interpreted that a higher concentration of polymer or a lower level of organic solvents produced a more viscous dispersion, which formed larger droplets and consequently larger microsponges obtained.

\section{Entrapment efficiency}

The level of organic solvent and level of polymer also had significant influence on the entrapment efficiency. The entrapment efficiency was observed to increase with an increase in the level of organic solvent that can be attributed to better solubilisation of the drug in the organic medium. The Higher volume of the organic solvent resulted in the more uniform mixing of the drug and polymer resulting in a more uniform matrix with high drug entrapment efficiency. Microsponges F1, F4 and F 9 with high level of organic solvent had a high percentage of EE $58.02 \%, 59.05 \%$, and $60.82 \%$ respectively. Whereas Microsponges F2 and F7 had the lowest percentage of entrapment efficiency, i.e. $35.56 \%$ and $46.14 \%$ due to low level of organic solvent. Similarly, on increasing polymer content entrapment efficiency, increased, i.e. (F1) $58.02 \%$ and (F8) $54.87 \%$ had a high entrapment efficiency, whereas microsponges with low level of polymer content had less entrapment efficiency i.e. (F2) $35.56 \%$ and (F6) $47.40 \%$ (Table II).

Along with above two factors a third factor, i.e. particle size also found to have an impact on the entrapment efficiency. The observations suggested that entrapment efficiency of the microsponges increased with the decrease in the particle size. Consequently F4 and F9 with particle size $42.15 \mu \mathrm{m}$ and $58.31 \mu \mathrm{m}$ had high $\mathrm{EE} \%$, i.e. $59.05 \%$ and $60.82 \%$, whereas F2 and F7 with particle size $61.22 \mu \mathrm{m}$ and $75.02 \mu \mathrm{m}$ had low EE i.e. \% $35.56 \%$ and $46.14 \%$ respectively. Therefore, Particle size also had an impact on the entrapment efficiency, but it was not statistically significant. Drug Content and Drug Loading of microsponge's ranged from $52.2 \%(\mathrm{~F} 2)$ to $85.2 \%$ (F9) and $15.98 \%$ (F6) to $39.75 \%$ (F4) respectively (Table II).

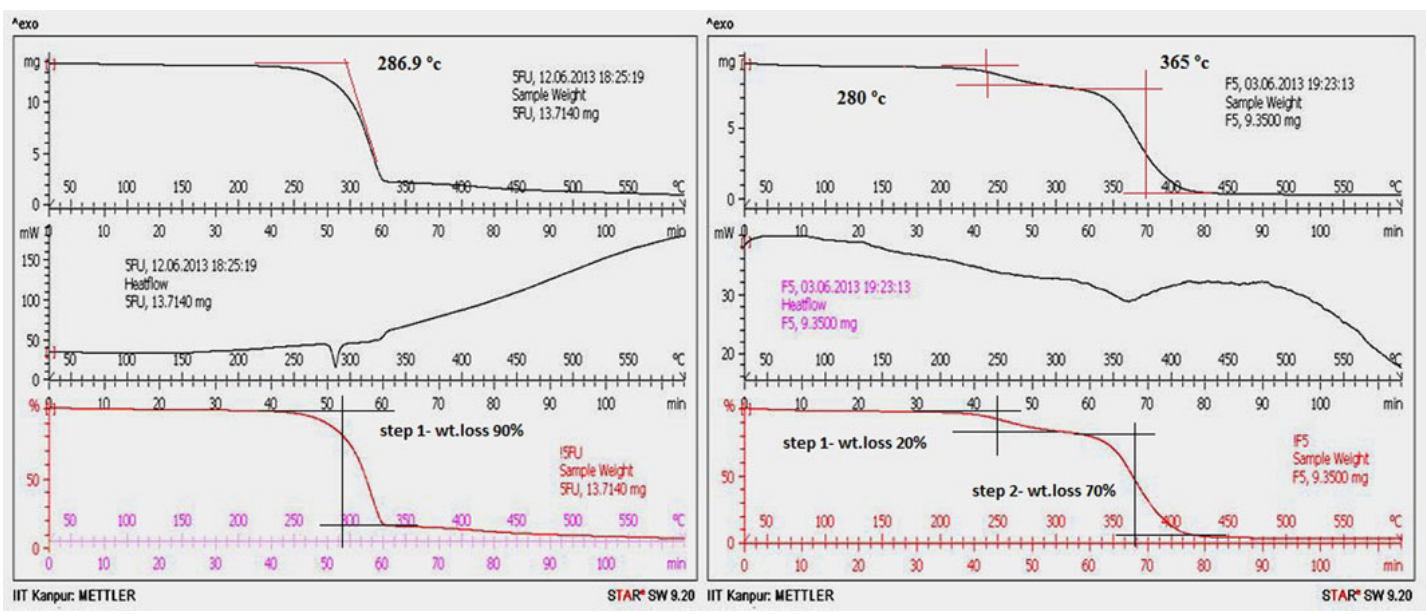

FIGURE 3 - TGA-DSC thermograms of pure 5-FU drug and 5-FU loaded Microsponges. 
TABLE II - Compilation of evaluation parameters of 5-FU loaded microsponges

\begin{tabular}{lccccc}
\hline Formulation code & Particle size $(\mu \mathrm{m})$ & Drug content $(\%)$ & Drug loading $(\%)$ & EE $(\%)$ & \% CDR \\
\hline F1 & $69.40 \pm 1.34$ & $79.01 \pm 0.52$ & $21.97 \pm 0.09$ & $58.02 \pm 0.20$ & $95.92 \pm 0.12$ \\
F2 & $61.22 \pm 0.65$ & $52.20 \pm 1.06$ & $25.48 \pm 0.14$ & $35.56 \pm 0.32$ & $93.69 \pm 0.07$ \\
F3 & $61.34 \pm 0.34$ & $84.54 \pm 0.21$ & $23.76 \pm 0.54$ & $50.27 \pm 0.26$ & $92.54 \pm 0.11$ \\
F4 & $42.15 \pm 0.28$ & $69.29 \pm 0.43$ & $39.75 \pm 0.17$ & $59.05 \pm 0.31$ & $97.07 \pm 0.13$ \\
F5 & $71.48 \pm 0.42$ & $72.43 \pm 1.15$ & $15.98 \pm 0.23$ & $50.02 \pm 0.19$ & $94.54 \pm 0.03$ \\
F6 & $55.32 \pm 0.25$ & $57.65 \pm 0.26$ & $31.32 \pm 0.08$ & $47.40 \pm 0.16$ & $90.52 \pm 0.02$ \\
F7 & $75.02 \pm 0.34$ & $58.39 \pm 0.72$ & $26.98 \pm 0.11$ & $46.14 \pm 0.37$ & $93.48 \pm 0.06$ \\
F8 & $65.31 \pm 0.92$ & $76.58 \pm 0.16$ & $19.71 \pm 0.21$ & $54.87 \pm 0.31$ & $91.78 \pm 0.15$ \\
F9 & $58.31 \pm 0.28$ & $85.01 \pm 0.29$ & $27.93 \pm 0.14$ & $60.82 \pm .015$ & $97.58 \pm .0 .02$ \\
F10 & 50.5838 & - & - & 59.3045 & 97.2196 \\
\hline
\end{tabular}

+ Predicted value, \% EE: Percent Entrapment Efficiency, \% CDR: Percent Cumulative Drug Release. *All the values are expressed in Mean $\pm \mathrm{SD}$

In vitro drug release study

The percent cumulative drug release in the SCF was observed between $90.52 \%$ (F6) to $97.58 \%$ (F9) suggesting the ability of the microsponges to release the drug completely (Table II). All the formulations followed zero order release kinetics (Figure 4) except F2 and F8 that followed Higuchi and Peppas release kinetics. Zero order release of drug from microsponges, has been reported by researchers (Devrim, Canefe, 2006). The mechanism of drug release from microsponges as explained by various researchers is co-relatable to its porous surface. The porous surface of the carrier particle enables easy penetration of the release media and its accessibility to the entrapped drug molecule. In case of F2 and F4, a high initial rate of the drug release in 2-3 h was observed due to the surface adsorbed drug molecule that underwent quick release to attain the Equilibrium with the dissolved drug molecule, Additionally, as suggested by various research reports, control on the drug release can also be achieved by uniform mixing of the drug and polymer in organic media to form homogenous phase.F2 and F7 formulated with low levels of polymer and organic phase might have resulted in the improper encapsulation of the 5-FU in the ERS 100 matrix. Due to this, majority of the drug molecules resided on the particulate surface as adsorbed molecules and had the probability of undergoing quick solubilisation and hence quick drug release. But after achieving equilibrium, the rate of drug release decreased. This effect was not predominant in $\mathrm{F} 9$ as it is constituted of intermediate level of ERS and high level of organic phase. While in F5, the release fitted first order model that may be due to the fact that the drug release from the polymeric microsponge occurs on transition of the polymer, and as the amount of

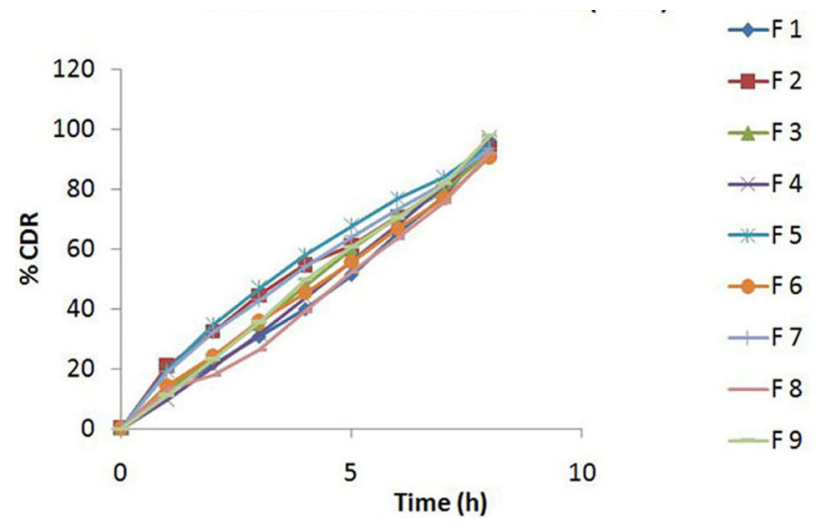

FIGURE 4 - In vitro drug release profile of 5-FU loaded microsponge formulations (F1-F9).

polymer in microsponges increases the time required for phase conversion also increases. Thus, in F8, the initial drug release was due to the adsorbed molecules but with the lapse of time, ERS layer underwent transition resulting in the abrupt or burst release of 5-FU.

\section{Statistical analysis}

Statistical analysis was done by Design expert software version 8.0.7.1 (Stat-Ease, Inc., Minneapolis, USA) and the second order polynomial equations were derived. The statistical model incorporating interactive and polynomial terms was utilized to evaluate the responses. Response surface plot (Figure 5) and 3-D Bar Graph (Figure 6) clearly depicts the effects of independent variables, i.e. varying the levels of volume of organic solvent and polymer content over dependent variables (i.e. Particle size, \% EE and \% CDR). 

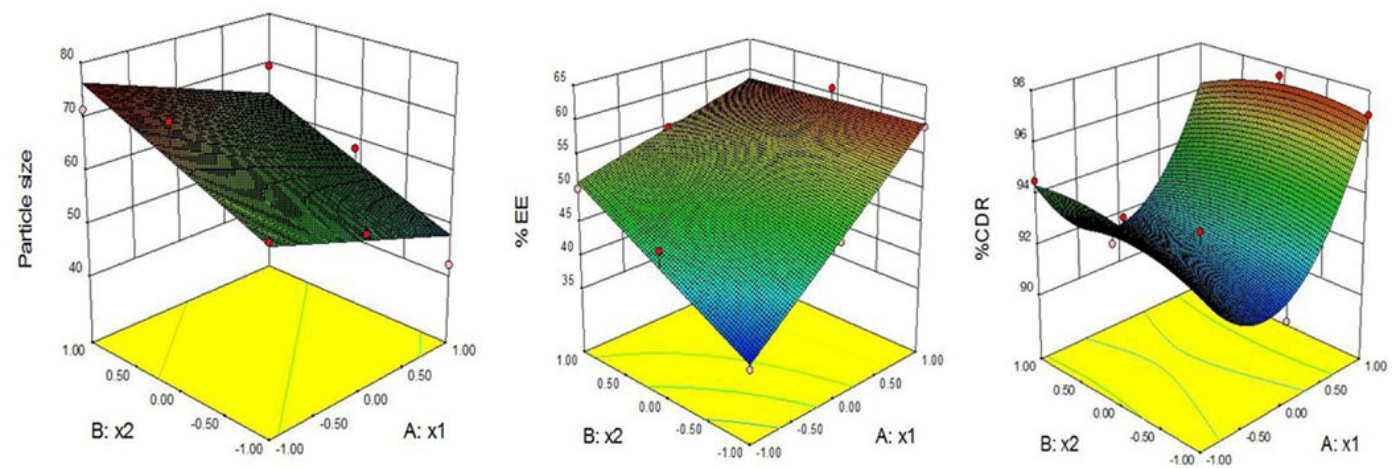

FIGURE 5 - Response surface plot depicting the influence of independent variables over dependent variables.
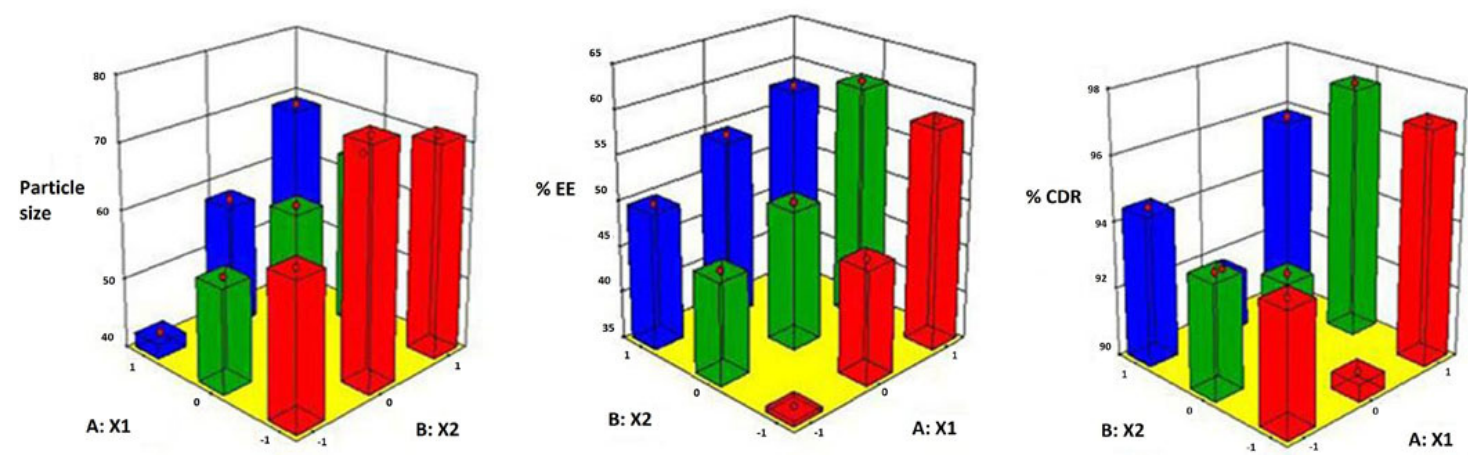

FIGURE 6 - 3D bar graph depicting the influence of independent variables over dependent variables.

\section{Factorial equation for particle size}

The Response Surface linear model generated for particle size was found to be significant with an $F$-value of $11.30(\mathrm{p}<0.0500)$ and correlation coefficient of 0.9824 .

Particle Size $\left(\mathrm{Y}_{1}\right)=62.17-6.31 \mathrm{X}_{1}+7.92 \mathrm{X}_{2}-1.52 \mathrm{X}_{1}{ }^{2}+$ $2.72 \mathrm{X}_{2}^{2}+3.94 \mathrm{X}_{1}^{2} \mathrm{X}_{2}+3.06 \mathrm{X}_{1} \mathrm{X}_{2}^{2}-2.03 \mathrm{X}_{1}^{2} \mathrm{X}_{2}^{2}$

The co-efficient of $X_{1}$ is negative, indicating that when the volume of organic solvent increased, the particle size decreased, whereas the positive coefficient of $\mathrm{X}_{2}$ indicates that particle size increased on increasing polymer content. The $\mathrm{P}$ value for variable $\mathrm{X} 1$ and $\mathrm{X} 2$ were 0.0252 and 0.0099 respectively $(\mathrm{p}<0.0500)$ indicated that both the independent variables show significant effect on dependent variable i.e. particle size.

\section{Factorial equation for \% EE}

The Response Surface linear model generated for particle size was found to be significant with an $F$-value of 63.59 ( $p<0.0500)$ and correlation coefficient of 0.9745 .

$\% \operatorname{EE}\left(Y_{2}\right)=51.350+7.695 X_{1}+3.483 X_{2}-3.872 X_{1} X_{2}$

The positive co-efficient of $\mathrm{X}_{1}$ and $\mathrm{X}_{2}$ indicates that
$\%$ EE increases on increasing volumes of organic content as well as polymer content. Whereas the combination of independent variables $\mathrm{X}_{1} \mathrm{X}_{2}$ had a negative influence on $\% \mathrm{EE}$. The $\mathrm{P}$ value for variable $\mathrm{X} 1, \mathrm{X} 2$ and $\mathrm{X}_{1} \mathrm{X}_{2}$ were $0.0001,0.0031$ and 0.0047 respectively $(p<0.0500)$ show that both the independent variables as well as combination of independent variable had a significant effect on dependent variable i.e. \% EE.

\section{Factorial equation for \% CDR}

The Response Surface linear model generated for $\%$ CDR was found to be significant with an $F$-value of 11.55 $(\mathrm{p}<0.0500)$ and correlation coefficient of 0.9506 .

$$
\begin{aligned}
& \% \operatorname{CDR}\left(\mathrm{Y}_{3}\right)=92.022+1.476 \mathrm{X}_{1}+3.766 \mathrm{X}_{1}^{2}+0.160 \mathrm{X}_{2} \\
& -0.613 \mathrm{X}_{2}{ }^{2}-0.500 \mathrm{X}_{1} \mathrm{X}_{2}
\end{aligned}
$$

According to above factorial equation Independent variables $\mathrm{X}_{1}, \mathrm{X}_{1}{ }^{2}$ and $\mathrm{X}_{2}$ had a positive influence on \% CDR. Whereas the combination of independent variables $\mathrm{X}_{1} \mathrm{X}_{2}$ and $\mathrm{X}_{2}^{2}$ had a negative influence on $\% \mathrm{CDR}$. The $\mathrm{X}_{1}$ and $\mathrm{X}_{1}{ }^{2}$ with $\mathrm{p}$ value 0.0250 and 0.0087 respectively, were significant model terms $(\mathrm{p}<0.0500)$ whereas $\mathrm{X}_{2}, \mathrm{X}_{1} \mathrm{X}_{2}$ and $\mathrm{X}_{2}^{2}$ were insignificant model terms. 


\section{Validation of the experimental design}

The results of experimentally observed responses and those predicted by mathematical models along with the percentage prediction errors were compared. The prediction error in the response parameters ranged between 0.51 and $1.15 \%$ with the value of absolute error of $1.28 \pm 0.70 \%$. Lower values of error indicate the high prognostic ability of factorial equation and counter plot methodology. "Adeq Precision" measures the signal to noise ratio. A ratio greater than 4 is desirable. The ratio of 8.505 indicates an adequate signal. Thus, this model can be used to navigate the design space.

\section{Selection of optimized formulation}

Microsponge formulation F4 with highest desirability factor of 0.944 having smallest particle size of $42.15 \pm 0.28 \mu \mathrm{m}$, maximum \% entrapment efficiency and $\%$ CDR of $59.05 \pm 0.31$ and $97.07 \pm 0.13$ respectively was selected as optimized formulation. Ramps reports clearly depict criteria's for selection of optimized formulation (Figure 7). F4 was further used for preparation of colon target capsules.

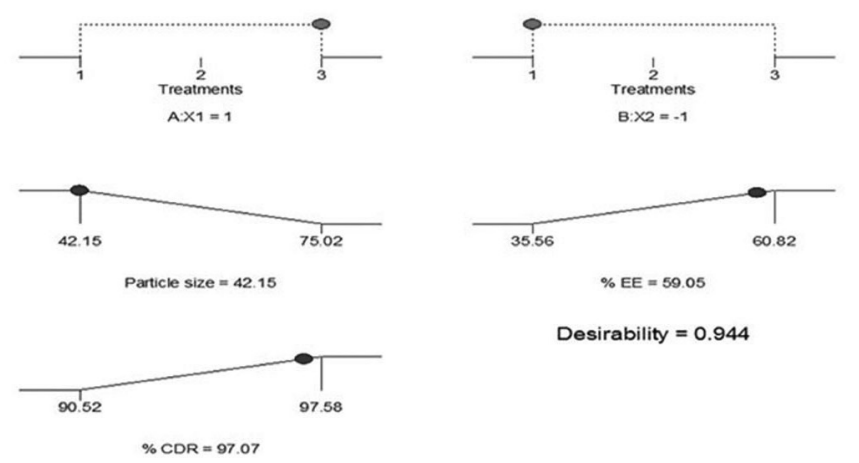

FIGURE 7 - Numerical optimization ramps report.

\section{Modification of pectin to calcium pectinate}

Use of Calcium pectinate beads as a plug in colon target capsules was a novel step and the rationale behind this was that calcium pectinate (the insoluble salt of pectin) is not degraded by gastric or intestinal enzymes, but will be degraded by colonic pectinolytic enzymes and hence now our formulation would be microbial triggered. Calcium pectinate is a natural polymer which can be used as a major component or filler in pharmaceutical composition that could be degraded by only colonic enzymes (Jain, Gupta, Jain, 2007). Pectin is one of the most widely investigated polysaccharides in the colon-specific drug delivery. It can be broken down by pectinase enzymes produced by anaerobic bacteria in the colon and control the drug release by this principle. It can also act via the $\mathrm{pH}-$ and time controlled mechanisms. However, due to high water solubility and swelling, pectin is not capable of shielding the drug effectively during the passage through the stomach and small intestine. Therefore Pectin with low degrees of methoxylation (i.e., low methoxypectins or LM pectin) was cross-linked with calcium ions $(\mathrm{Ca} 2+$, divalent cations) to produce $\mathrm{Ca}$ - pectinate networks that were less water soluble (Bourgeois et al., 2006). Indeed, $\mathrm{Ca} 2+$ ions form "bridges" between the free carboxylated groups of galacturonic acid moieties. The network that is formed has been described by Grant et al. under the name of «egg-box model». Pectin with DM $<50 \%$ (i.e., LM pectin) was used because it contains more free carboxylic group than high methoxy pectin (HM pectin). Therefore, cross-linking between divalent cations (e.g., $\mathrm{Ca} 2+$ ) and free carboxylic groups of the pectin are more evident in LM pectin than HM pectin (Badve et al., 2007). The spherical beads were easily prepared without any sophisticated instrument due to ionic interaction between the negatively charged carboxylic groups of pectin molecules and the positively charged divalent calcium ions which led to intermolecular cross-linking and instantaneously produced gelled sphere (Sriamornsak, Thirawong, Puttipipatkhachorn, 2005).

\section{Characterization of calcium pectinate beads}

\section{Size, surface morphology and rheological characterization}

Particle size of calcium pectinate beads was of approx $105.22 \pm 3.36 \mu \mathrm{m}$. SEM of pectin demonstrated smooth doughnut shaped particles more or less, of uniform size (Figure $8 \mathrm{G}$ ) and calcium pectinate beads were spherical with smooth surfaced (Figure $8 \mathrm{H}$ ). Analysis of the rheological characteristics of calcium pectinate confirmed good rheological properties with bulk and tapped density of $0.504 \mathrm{~g} / \mathrm{cm}^{3}$ and $0.558 \mathrm{~g} / \mathrm{cm}^{3}$, Carr's compressibility index of $9.67 \%$ and Angle of repose of $20.56^{\circ}$ indicated good flow properties of calcium pectinate beads.
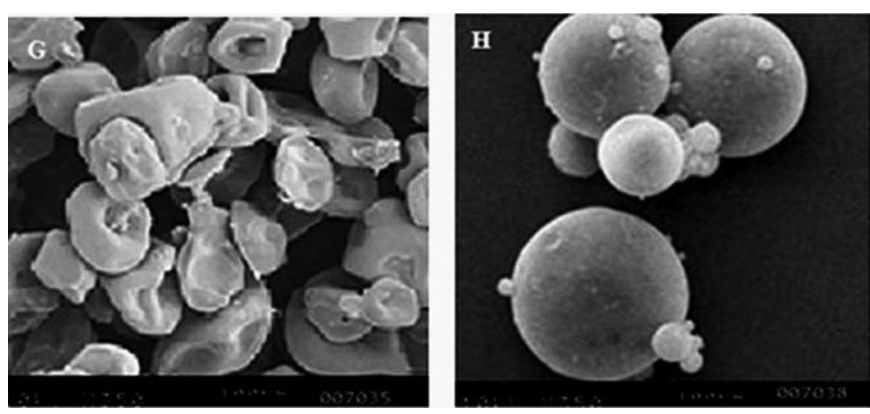

FIGURE 8 - SEM of Pectin $(G)$ and Calcium Pectinate beads $(H)$. 


\section{- $\quad$ Swelling characteristics}

Pectin and calcium pectinate were compared for their swelling characteristics. No significant swelling was observed for calcium pectinate (swelling ratio of $0.11 \pm$ 0.04 ) as compared to pectin, which swelled considerably with a swelling ratio of $0.98 \pm 0.02$. The reduction in swelling of the calcium pectinate in SIF ( $\mathrm{pH}$ 7.4) presents its feasibility to be used as a carrier for the colon-targeted drug delivery.

\section{Preparation of enteric coated HPMC capsules}

EUDRAGIT ${ }^{\circledR}$ L and $S$ grades are suitable for enteric coatings and are specifically used for controlled release in the colon (Ramasamy et al., 2011). Coatings on the gelatin capsules often suffer from insufficient adhesion between the shell and the coating. Thus, previous workers in the area of enteric coating have found it necessary to pre-coat gelatin capsules with, for instance, a cellulose derivative, either to promote adhesion of polymers to the capsule shell or to improve gastric-resistance (Cole et al., 2002). When the capsule itself is made of a cellulose derivative it would be expected, based on the experience with enteric coating of tablets with a pre-coating of HPMC, that a pre-coating step could be eliminated. Gelatin capsules have a very glossy surface due to the fact that the amount of regular reflection from the surface is high and the amount of diffuse reflection is low. In contrast, HPMC capsules have a visually matt surface with a greater amount of diffuse reflection, suggesting a more irregular surface. SEM's of the surface of HPMC and gelatin capsules are shown in Figure 9 (I) and Figure 9 (J) where this difference is clearly visible. During the coating process the temperature of the capsule bed reaches $25-27^{\circ} \mathrm{C}$. At this temperature HPMC is soluble and will start to dissolve in the eudragit film providing a strongly adhesive surface. Gelatin, on the other hand, is only slightly soluble at this temperature and its surface characteristics will remain virtually unchanged.
Figure $9(\mathrm{~K})$ shows SEM of the cross-section of a cleaved surface through an HPMC capsule coated with EdS100 solution. The contours of the coating material are seen to follow the irregular surface of the HPMC capsule. It is suggested that the high strength of the bond between HPMC and the film is a combination of the irregular surface and the tackiness of the partially dissolved surface. No pores or cracks can be observed, due to the well controlled coating process. In addition, the critical area of overlap between the cap and the body of the capsule is also covered with EdS100 polymers to ensure gastric integrity.

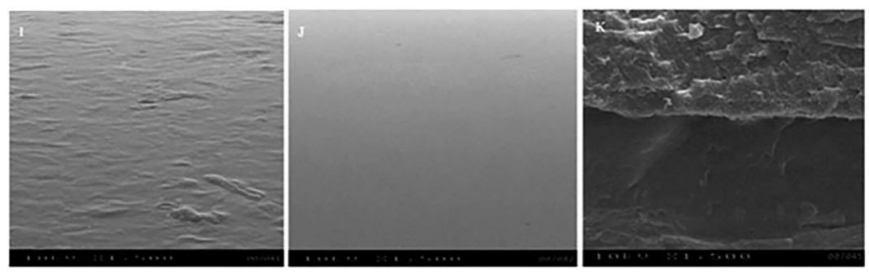

FIGURE 9 - SEM of a cross section of HPMC capsule surface (I), Gelatine capsule surface (J), and HPMC capsule surface coated with Eudragit S 100 (K).

\section{Evaluation of colon target enteric coated HPMC capsules}

Integrity test of enteric coated HPMC capsules

Results of integrity test are shown in Table III. ECHC-3, ECHC14 and ECHC15 which did not dissolve in $\mathrm{pH} 5.5$ buffers were selected for further in vitro drug release study in simulated colonic fluid.

In vitro drug release study

In vitro drug release study was conducted in $\mathrm{pH}$ change method as per USP protocol ( $2 \mathrm{~h}$ in SGF, $2-5 \mathrm{~h}$ in SIF and 5-24 $\mathrm{h}$ in the SCF) and the results are shown in Table IV. The immediate release marketed formulation showed almost total release in $4 \mathrm{~h}$ and the pure drug in $3 \mathrm{~h}$. Nearly complete drug release of microsponges in

TABLE III - Integrity test of enteric coated HPMC capsules

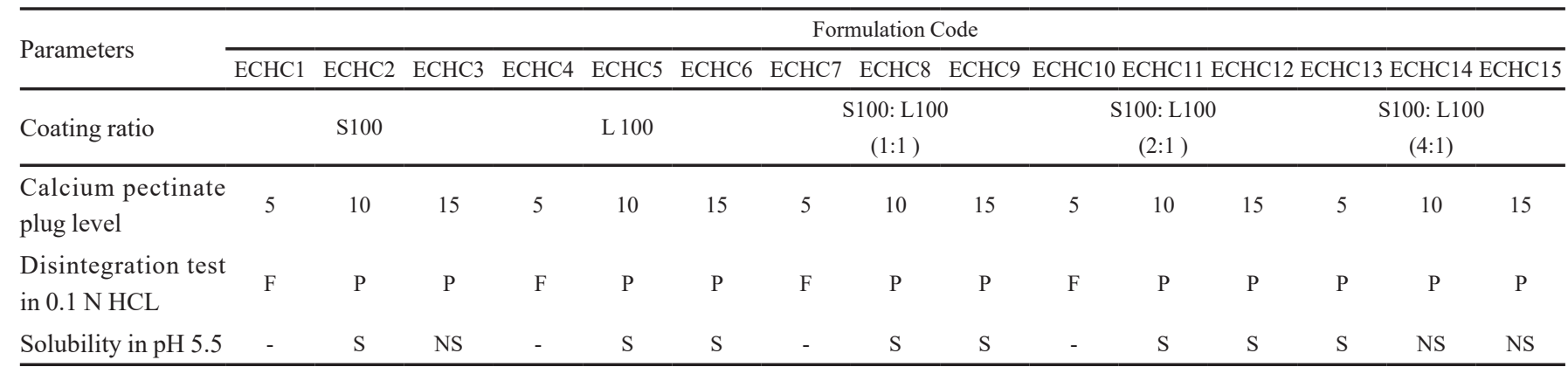

$* \mathrm{~F}=$ Fail, $\mathrm{P}=$ Pass, $\mathrm{S}=$ Soluble, $\mathrm{NS}=$ Not Soluble 
HPMC capsules $(97.07 \%)$ in $8 \mathrm{~h}$ indicated the need for enteric coating of capsules for colon delivery (Figure 10). Enteric coated HPMC capsules ECHC-3, ECHC14 and ECHC-15 showed no drug release in simulated gastric fluid ( $\mathrm{pH} 1.2$ ) up to $2 \mathrm{~h}$ indicating the intactness of the applied coating. On exposure to simulated intestinal media, capsules coated with blend of EdS-100: EdL-100 showed the earlier drug release as compared to capsules coated with only EdS-100. As the $\mathrm{pH}$ of solubilisation of EdL-100 is 6 and that of EdS-100 is 7.0, EdL-100 gets dissolved first and form pores. Calcium pectinate beads also become hydrated and forms a viscous gel layer that slows down further seeping -in of dissolution fluids and therefore release of 5-FU takes place by diffusion along with the erosion of eudragit layers (Sharma, Philip, Pathak, 2008). The formulations ECHC-14 and ECHC-15 released $15.01 \%$ and $14.56 \%$ of $5-\mathrm{FU}$ respectively, at the end of $5 \mathrm{~h}$ dissolution study in intestinal media. This indicated that in spite of the high water solubility of 5-FU, there was tight control of drug release in the physiological environment of the stomach and small intestine. However the integrity of ECHC -3, was maintained after $5 \mathrm{~h}$ studies with no drug release upto $5 \mathrm{~h}$ this indicated that drug released was highly retarded on coating with EdS-100 (ECHC -3) in comparison to blend of EdS-100: EdL-100 coating. Visual observation revealed small flakes of coatings occurred about $3.5 \mathrm{~h}$ from the beginning of the release experiment. The release of drug from the enteric-coated capsules can be explained by the pore formations and bursting/ flake formation of the coat due to the presence of high alkaline $\mathrm{pH}$ of dissolution media.

The ECHC-3 containing $15 \%$ calcium pectinate plug in ES 100 coated HPMC capsules appears to be promising as it did not release the cytotoxic 5-FU in the

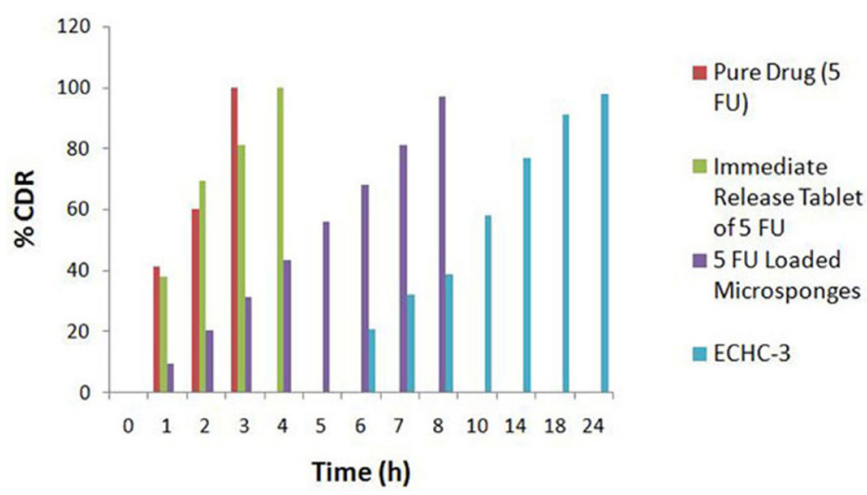

FIGURE 10 - Comparison of in vitro release profile of immediate release marketed tablet of 5-FU, pure 5-FU drug, 5-FU loaded microsponges and enteric coated HPMC capsules plugged with 5-FU loaded microsponges and calcium pectinate beads.

physiological environment of the stomach and small intestine. The relative advantage of ECHC-3 over the other formulations ECHC-14 and ECHC-15 also depend on its ability to release the drug in the physiological environment of the colon. Hence, after completing the dissolution study in $1.2 \mathrm{pH}$ and $6.8 \mathrm{pH}$, the dissolution study was carried out in simulated colonic fluids (with pectinase enzyme and without pectinase enzyme i.e. control study) for another $19 \mathrm{~h}$. The percentage of 5-FU released from ECHC-3 at the end of $24 \mathrm{~h}$ with pectinase enzyme was found to be $97.83 \pm 0.12 \%$, whereas in the control study (without pectinase enzyme in the dissolution medium) only 40.08 $\pm 0.02 \%$ of 5 -FU was released. This difference was found to be statistically significant $(p<0.001)$. This study shows that the release of 5-FU in a physiological environment of the colon is due to the microbial degradation of calcium pectinate plug in the presence of pectinase enzyme. The dissolution study was conducted without pectinase enzyme

TABLE IV - In vitro drug release profile of ECHC

\begin{tabular}{|c|c|c|c|c|c|c|}
\hline \multirow{2}{*}{ Time } & \multicolumn{6}{|c|}{ Cumulative \% Drug Release } \\
\hline & \multicolumn{2}{|c|}{ ECHC 3} & \multicolumn{2}{|c|}{ ECHC 14} & \multicolumn{2}{|c|}{ ECHC 15} \\
\hline $0-2 \mathrm{~h}$ at Gastric $\mathrm{pH}(1.2)$ & \multicolumn{2}{|c|}{ No release } & \multicolumn{2}{|c|}{ No release } & \multicolumn{2}{|c|}{ No release } \\
\hline $2-5 \mathrm{~h}$ in intestinal $\mathrm{pH}(6.8)$ & \multicolumn{2}{|c|}{ No release } & \multicolumn{2}{|c|}{$12.01 \pm 0.02$} & \multicolumn{2}{|c|}{$10.56 \pm 0.07$} \\
\hline Simulated Colonic pH 7.4 & Pectinase & Control Study & Pectinase & Control Study & Pectinase & Control Study \\
\hline 6 & $21.03 \pm 0.01$ & $8.17 \pm 0.02$ & $38.02 \pm 0.04$ & $18.03 \pm 0.02$ & $35.12 \pm 0.05$ & $14.06 \pm 0.01$ \\
\hline 8 & $39.04 \pm 0.12$ & $15.02 \pm 0.14$ & $50.04 \pm 0.06$ & $26.04 \pm 0.11$ & $49.07 \pm 0.13$ & $22.15 \pm 0.08$ \\
\hline 10 & $58.22 \pm 0.03$ & $22.08 \pm 0.13$ & $63.21 \pm 0.08$ & $31.21 \pm 0.07$ & $66.15 \pm 0.04$ & $28.07 \pm 0.13$ \\
\hline 14 & $77.01 \pm 0.06$ & $29.01 \pm 0.05$ & $76.14 \pm 0.01$ & $35.08 \pm 0.06$ & $79.22 \pm 0.11$ & $34.12 \pm 0.06$ \\
\hline 18 & $91.02 \pm 0.04$ & $33.09 \pm 0.06$ & $88.11 \pm 0.03$ & $39.01 \pm 0.11$ & $90.23 \pm 0.02$ & $40.01 \pm 0.02$ \\
\hline 24 & $97.83 \pm 0.12$ & $40.08 \pm 0.01$ & $96.05 \pm 0.12$ & $44.84 \pm 0.03$ & $97.01 \pm 0.08$ & $46.43 \pm 0.09$ \\
\hline
\end{tabular}

*All the values are expressed in Mean \pm SD 
(control study) to ensure that the drug was not released due to the mechanical erosion, which is likely to occur because of bowel movements in humans. Similarly formulations ECHC-14 and ECHC-15 released $96.05 \pm 0.05 \%$ and $97.01 \pm 0.08 \%$ of $5-\mathrm{FU}$ respectively in the presence of pectinase enzyme, whereas in control study, they released only $44.84 \pm 0.03 \%$ and $46.34 \pm 0.09 \%$ respectively. A significant difference was observed $(\mathrm{p}<0.001)$ in the amount of 5-FU released from formulations ECHC-14 and $\mathrm{ECHC}-15$ at the end of $24 \mathrm{~h}$ with a pectinase enzyme as compared to in vitro release without pectinase enzyme.

All the three formulations ECHC -3, ECHC-14 and ECHC-15 released almost complete drug by the end of $24 \mathrm{~h}$ in vitro release study in the presence of pectinase enzyme. The release profiles of all the three formulations were similar at the end of $24 \mathrm{~h}$ with no significant difference $(\mathrm{p} \leq 0.05)$. HPMC capsule provided a system of low permeability and a good barrier to drug diffusion at the $\mathrm{pH}$, where protection is required (Moawia, Tabakha, 2010). Variation in coating ratios had little influence on the dissolution profiles of microsponges confirming the robustness of the formulation and the better compatibility between HPMC and the polymethacrylate films. Thus, enteric coated HPMC capsules plugged with a matrix of 5-FU loaded microsponges and calcium pectinate proved to be potential candidate for targeted colonic delivery to treat colorectal cancer.

\section{ANIMAL STUDIES}

\section{In vivo roentgenography study}

In vivo $\mathrm{X}$-ray imaging allows the visualization of in vivo functioning of a colon specific drug delivery system, thereby ascertaining the location of drug release. The results of X-ray imaging studies are shown in Figure 11. Figure 11 (a) shows position of capsule just after the administration followed by its passage to stomach after $1.5 \mathrm{~h}$ in Figure 11 (b) thereby indicating that the capsule remains intact in the stomach, establishing in vivo efficiency of the coating of Eudragit L100 and Eudragit S 100 in preventing drug release in the gastric milieu. Figure 11 (c) depicts no significant difference in the integrity of capsules in comparison to Figure 11 (b), thereby indicating intactness of capsule in the small intestine at $3.5 \mathrm{~h}$. The capsule could be traced in the small intestine at $3.5 \mathrm{~h}$ (Figure11c), intestinal colon junction at $5 \mathrm{~h}$ (Figure $11 \mathrm{~d}$ ) and finally in colon at $7.5 \mathrm{~h}$ (Figure $11 \mathrm{e}$ ). At $10 \mathrm{~h}$ (Figure $11 \mathrm{f}$ ) the intact capsule could not be traced demonstrating its erosion in the colon. These images clearly demonstrate the efficiency of selected formulation (ECHC-3) for its capacity to traverse the intestine intact and deliver the drug for site specific targeting of 5-FU microsponges to the colon.
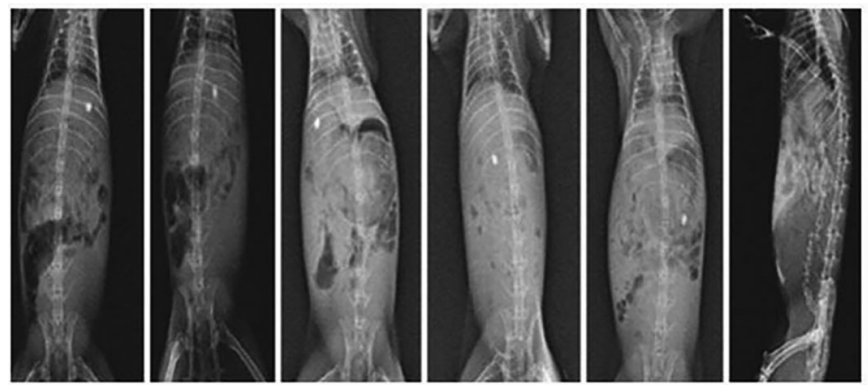

FIGURE 11 - X-ray images of New Zealand rabbit administered with colon targeted formulation (a) immediately after administration, (b) $1.5 \mathrm{~h}$ (stomach), (c) $3.5 \mathrm{~h}$ (small intestine), (d) $5 \mathrm{~h}$ (intestinal colon junction), (e) $7.5 \mathrm{~h}$ (colon) and (f) $10 \mathrm{~h}$ (rectum).

\section{In vivo pharmacokinetics study}

Figure 12 shows the plasma concentration $v s$. time profiles of 5-FU after administration of ECHC and the 5-FU aqueous solution to New Zealand white rabbits at a dose of $10 \mathrm{mg} / \mathrm{kg}$ respectively. Colon specific absorption of releasing 5-FU affected its pharmacokinetic parameters. After oral administration of the 5-FU solution, the drug was detected rapidly in plasma. The maximum concentration of 5-FU was $20 \mu \mathrm{g} / \mathrm{mL}$ after about $1 \mathrm{~h}$. Thereafter, the plasma concentration decreased quickly and the drug was not detectable as soon as $8 \mathrm{~h}$. The elimination half life was $0.12 \pm 0.03 \mathrm{~h}$. While in case of colon targeted enteric coated capsules (ECHC), 5-FU appeared in plasma after $6 \mathrm{~h}$ (lag time) of administration with a $C$ max of $14 \mu \mathrm{g} / \mathrm{mL}$ at $25 \mathrm{~h}$. A lag time of $6 \mathrm{~h}$ for the developed colon targeted enteric coated capsules indicated the ability of the colon-targeted formulation to prevent the release of 5-FU in the stomach and small intestine. The $C \max , T \max , t_{1 / 2}$ and $A U C_{0-\infty}$ were significantly different from those of the aqueous solution. The $C \max$ of colon-targeted formulation was significantly $(\mathrm{p}<0.001)$ less than the $C \max$ of $5 \mathrm{FU}$ solution, suggested reduced systemic absorption of the drug from ECHC-3. This means that a larger fraction of the drug was available on the colonic surface for local action. $\mathrm{AUC}_{0-\alpha}$ for aqueous solution and colontargeted formulation was found to be $62.5543 \mu \mathrm{g} \mathrm{h} / \mathrm{mL}$ and $49.3412 \mu \mathrm{g} \mathrm{h} / \mathrm{mL}$, respectively. Consequently the $\mathrm{Fr}$ (relative bioavailability) of the colon-targeted tablet was determined as $70.18 \%$. Thus, in vivo pharmacokinetic studies of enteric coated HPMC capsules plugged with calcium pectinate beads and 5-FU loaded microsponges exhibited increased lag time, delayed $t$ max, decreased Cmax and reduced bioavailability. It can thus be concluded 


\section{In Vivo Pharmacokinetic Profile}

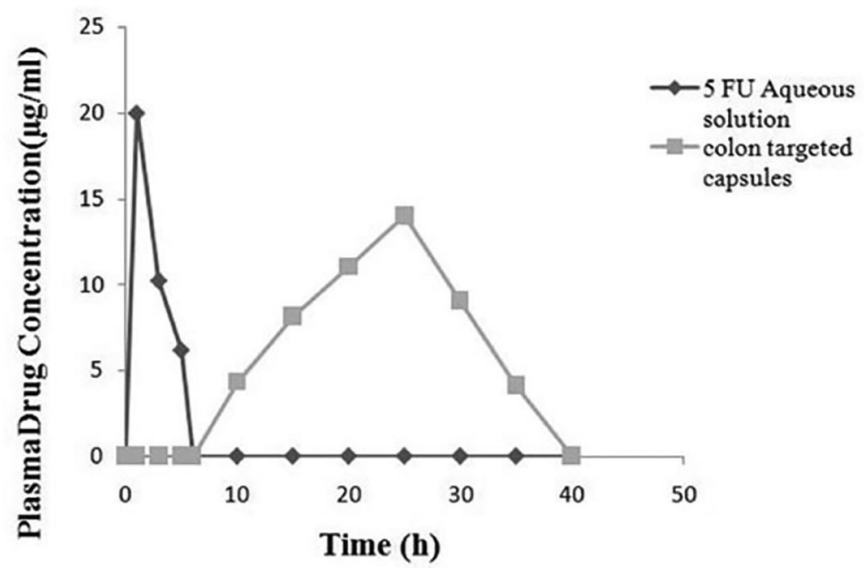

FIGURE 12 - In vivo pharmacokinetic profile of 5-FU in New Zealand white rabbits following administration of 5-FU aqueous solution and developed colon targeted capsules.

that the developed colon targeted formulation has the ability to avoid the drug release in the upper GIT, but can release the active agent specifically in the colon exert local action with reduced systemic exposure.

\section{CONCLUSION}

A novel colon targeted drug delivery system that combined two approaches, i.e. $\mathrm{pH}$-sensitive delivery as well as degradation by bacterial enzymes in the colon environment was successfully developed. This study clearly indicated that enteric coated HPMC capsules plugged with 5-FU loaded microsponges along with $15 \%$ calcium pectinate beads provided a tight control over the drug release in the physiological environment of the stomach and small intestine in spite its high water solubility. Matt surface of HPMC capsule provided a good substrate for adhesion of enteric coating polymers and calcium pectinate beads also proved to be a suitable carrier for colon targeted system. Thus, the developed colon targeted drug delivery system proved to be more patient compliant by providing a better mode of treatment over present intermittent chemotherapy by injection or infusion.

\section{ACKNOWLEDGEMENTS}

The authors are thankful to IIT Kanpur and Diya Labs for providing PXRD, TGA and SEM facility. We would also like to acknowledge Shalaks Pharmaceuticals, Evonik Labs and ACG Associated Capsules Pvt. Ltd, SciTech Centre for generous gift samples of 5-FU, Eudragit polymers and HPMC capsules.

\section{REFERENCES}

BADVE, S. S.; SHER, P.; KORDE, A.; PAWAR, A. P. Development of hollow/porous calcium pectinate beads for floating-pulsatile drug delivery. Eur. J. Pharm. Biopharm., v.65, n.1, p.85-93, 2007.

BAE, S. E.; SON, J. S.; PARK, K.; HAN, D. K. Fabrication of covered porous PLGA microspheres using hydrogen peroxide for controlled drug delivery and regenerative medicine. J. Control. Release, v.133, n.1, p.37-43, 2009.

BOURGEOIS, S.; GERNET, M.; PRADEAU, D.; ANDREMONT, A.; FATTAL, E. Evaluation of critical formulation parameters influencing the bioactivity of betalactamases entrapped in pectin beads. Int. J. Pharm., v.324, n.1, p.2-9, 2006.

CHICKPETTY, S. M.; RAGA, B. V. Formulation, in vitro drug release and in vivo human $\mathrm{X}$-ray investigation of polysaccharide based drug delivery systems for targeting 5 -fluorouracil to the colon. Braz. J. Pharm. Sci., v. 49, n.2, p.263-273, 2013.

COLE, E. T.; SCOTT, R. A.; CONNOR, A. L.; WILDING, I. R.; PETEREIT, H. U.; SCHMINKE, C. Enteric coated HPMC capsules designed to achieve intestinal targeting. Int. J. Pharm., v.231, n.1, p.83-95, 2002.

COSTA, P.; LOBO, J. M. S. Modeling and comparison of dissolution profiles. Eur. J. Pharm. Sci., v.13, n.2, p.123$133,2001$.

DEVRIM, B.; CANEFE, K. Preparation and evaluation of modified release ibuprofen microspheres with acrylic polymers (Eudragit) by quasi emulsion solvent diffusion method: effect of variables. Acta Pol. Pharm., v.63, n.6, p.521-534, 2006.

GRAVES, R.; MOISEYEV, R.; PAMUJULA, S.; PRAETORIUS, N.; HAVEN, K.; BOSTANIAN, L. Spherical biodegradable microsponge particles for drug delivery. Am. Assoc. Pharm. Sci. J., v.7, n.1, p.52, 2005.

HUYGHEBAERT, N.; VERMEIRE, A.; REMON, J. Alternative method for enteric coating of HPMC capsules resulting in ready-to-use enteric-coated capsules. Eur. J. Pharm. Sci., v. 21, p. 617-23, 2004. 
JAIN, A.; GUPTA, Y; JAIN, S.K. Potential of calcium pectinate beads for target specific drug release to colon. J. Drug Target., v.15, n.4, p.285-294, 2007.

LEE, J. S.; CHAE, G. S.; KUN, A. T.; KHANG, G. Preparation of 5-fluorouracil-loaded poly (1-lactide-co-glycolide) wafer and evaluation of in vitro release behaviour. Macromolecules, v.11, n.3, p.183-188, 2003.

MOAWIA, M.; TABAKHA, A. L. HPMC capsules: current status and future prospects. J. Pharm. Pharm. Sci., v.13, n.3, p.428-442, 2010.

ORLU, M.; CEVHER, E.; ARAMAN, A. Design and evaluation of colon specific drug delivery system containing flurbiprofen microsponges. Int. J. Pharm., v.318, n.1-2, p.103-117, 2006.

RAMASAMY, T. G.; KANDHASAMI, U. S.; RUTTALA, H.; SHANMUGAM, S. Formulation and evaluation of xanthan gum based aceclofenac tablets for colon targeted drug delivery. Braz. J. Pharm. Sci., v.47, n.2, p.299-311, 2011.

SHARMA, V.; PHILIP, A.K.; PATHAK, K. Modified polysaccharides as fast disintegrating excipients for orodispersible tablets of roxithromycin. AAPS Pharm. Sci. Tech., v.9, n.1, p.87-94, 2008.
S R I A M O R N S A K, P.; T H I R A W O N G, N . ; PUTTIPIPATKHACHORN, S. Emulsion gel beads of calcium pectinate capable of floating on the gastric fluid: effect of some additives, hardening agent or coating on release behavior of metronidazole. Eur. J. Pharm. Sci., v.24, n.4, p.363-373, 2005.

SRIVASTAVA, R.; KUMAR, D.; PATHAK, K. Colonic luminal surface retention of meloxicam microsponges delivered by erosion based colon targeted matrix tablet. Int. J. Pharm., v.427, n.2, p.153-162, 2010.

WOLPIN, B. M.; MAYER, R. J. Systemic treatment of colorectal cancer. Gastroenterology, v.134, n.5, p.1296$1230,2008$.

ZHANG, Y.; LANG, M.; TANG, X.; LI, L.; SHEN, X.; Folatefunctionalized nanoparticles for controlled 5-Fluorouracil delivery. J. Colloid Interface Sci., v.354, n.1, p.202-209, 2011.

Received for publication on $03^{\text {rd }}$ August 2014 Accepted for publication on $09^{\text {th }}$ June 2015 
